\title{
The potential of silk fibroin as a polymer composite reinforcement for bone implant materials
}

\author{
Purnomo $^{1,{ }^{*}}$, Putu Hadi Setyarini ${ }^{2}$ and Ana Hidayati Mukaromah ${ }^{3}$ \\ ${ }^{1}$ Dept. of Mechanical Engineering, Universitas Muhammadiyah Semarang, 50273 Semarang, \\ Indonesia \\ ${ }^{2}$ Dept. of Mechanical Engineering, Brawijaya University,Malang, 65145 Malang, Indonesia \\ ${ }^{3}$ Dept. of Health Analyst, Universitas Muhammadiyah Semarang, 50273 Semarang, Indonesia
}

\begin{abstract}
Silk fibroin is an outstanding material because of their biocompatible and excellent mechanical properties. This review article is focused on silk fibroin and silk fibroin-based composites that are used as biomaterials and their potential for composite reinforcing materials for artificial bone engineering. This material is chosen because it is biocompatible, low biodegradable, as well as ease of fabrication, as well as a variety of good mechanical behavior. The first part provides the introduction of some polymer-based materials used as biomaterials. The second part is more focused on silk fibroin applications as biomaterials that include silk fibroin structure, biocompatibility, degradation, immunological responses, sterilizability, drug delivery for osteogenesis, and fibroin reinforcement materials silk.
\end{abstract}

\section{Introduction}

Over the last years, biomaterials attract attention due to the increasing need for implantable materials. The polymeric materials have been widely used for implant materials due to biocompatible, their simplicity of manufacture as well as unique mechanical, thermal, and chemical behavior which are favorable in many kinds of application [1]. Some synthetic polymers include polymethyl methacrylate (PMMA), polyether ether ketone (PEEK), and high-density polyethylene (HDPE) have been used for biomaterials as bone implant materials $[1,2-8]$. Bone defects due to trauma or other accidental injuries frequently require the reconstruction or other surgical actions [9]. Many people are subjected to bone graft surgery due to a skeletal imperfection or other defects. The bone experts prefer autografts or allografts in responding to the bone defect case, although this option often poses a bad risk to the patient. The autographs need additional surgical locations and limitation in supply, while allografts can cause an infection or disease transferral $[10,11]$.

Many naturally derived polymers have been assessed for application as biomaterials specifically collagen, chitosan, keratin, and silk fibroin [12-16]. Many materials have been studied for bone implant applications, especially bone tissue engineering [17-19]. The silk fibroin is one of them that makes the spotlight due to its exceptional mechanical properties

\footnotetext{
* Corresponding author: purnomo@unimus.ac.id
} 
which makes it a promising material for biomedical applications especially bone implants [20]. In addition, in the last 10 years, the number of publications and citations on silk fibroin has increased significantly [19]. This situation supports the importance of using silk fibroin as a bone implant material. This review is focused on highlighting the potential of silk fibroin as a reinforcement in bone implant materials from polymer composites.

\section{Silk fibroin application as biomaterials}

Silkworms consist of two main protein: sericin and silk fibroin. Removal of sericin from the silk fibroin (Figure 1) can be conducted by a degumming process, leaving only silk fibroin. The ascendancy of hydrophobic with short chain amino acids in the main continuity are the main constituents of the silk. The silk fibroin amino acids are composed of two distinct chain sub-component, i.e., light chains comprising nonrepetitive hydrophobic, and heavy chains wherein the amino acid series be composed of repeated hydrophobic blocks [21]. The non-covalent P25 glycoprotein is bound to a prearranged of six light and heavy chains [22, 23]. Major hydrophobic connected to minor hydrophilic domains promote silk the construction, strength, and imperishability of silk fibroin [24].

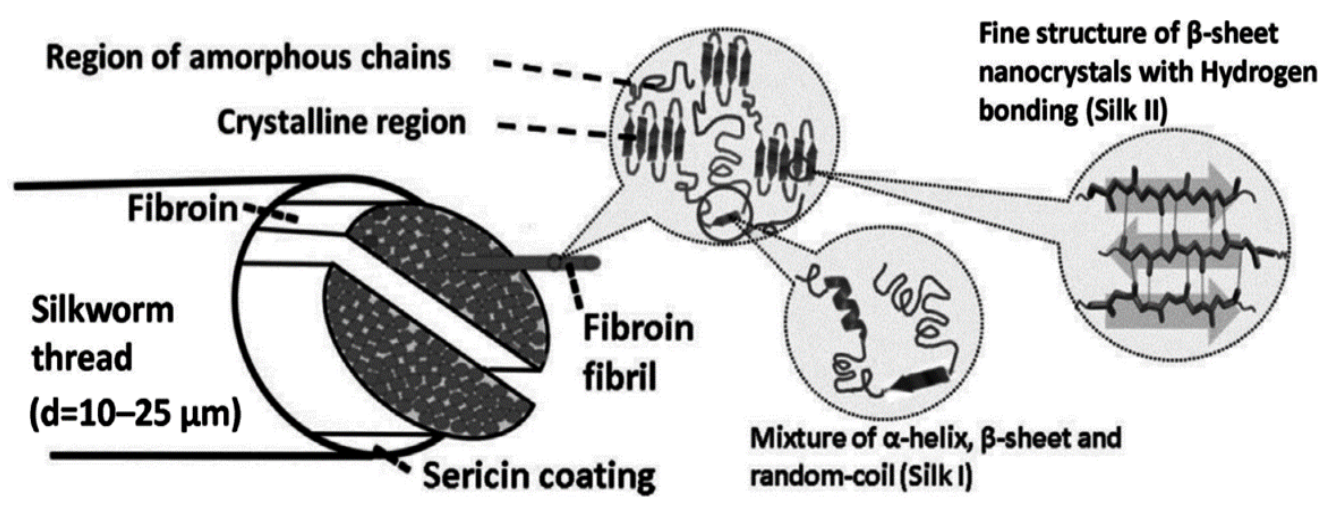

Fig. 1. Schematic illustration of the silk fibroin structure; $d$ indicates the single diameter of the silkworm. Reproduced from [25, 26].

Silks representing the unique family of structural proteins are biocompatible and degraded. It also offers a variety of superior mechanical properties. In fact, it offers a variety of properties that can be adapted to the treatment of aqueous solvents and may be chemically adjusted to fit the applications [27]. As a biomaterial, it is needed to provide the mechanical properties that functionally support the organs work in the human body. For this function, silk fibers have been investigated as biomaterials because of their successful functioning as stitching materials since several centuries ago [28]. Silk fibroin is an outstanding natural polymer that has been widely used as a biomaterial especially bone implant due to its excellent mechanical and biomedical behavior. 


\subsection{Biocompatibility}

One of the reasons silk fibroin is suitable for use as a biomaterial is its biocompatible nature to the human body. The silk fibroin scaffold and acellular collagen I/III scaffold were biocompatible and could be used as substitution of scaffolds for tissue engineering like the ear [29, 30]. Silk fibroin showed biocompatibility and no significant cytotoxic effects on phenotype and function of the cell [31,32]. This suggests that silk fibroin is suitable for tissue engineering like nerve applications. It has been reported that the implanted scaffolds of the fibroin-chitosan did not generate an inflammation effect, and it allows the host cells to create new blood vessels [33].

\subsection{Degradation}

Biomaterial degradation is an important consideration in the development of implantable material engineering. The United State Pharmacopeia [34] characterizes the silk fibroin as a non-degradable material. Nevertheless, many works reported that silk fibroin can be degraded given consideration that the extraneous body reactions can affect the silk fibroin degradation [35-37]. Silk fibroin degradation is advantageous in the use of biomedicine because the amino acids produced are well absorbed. the activity of phagocytotic and fibroblasts is strongly associated with in vivo degradation. Nevertheless, the enzyme did not play a notable part in degradation processes in vitro [38].

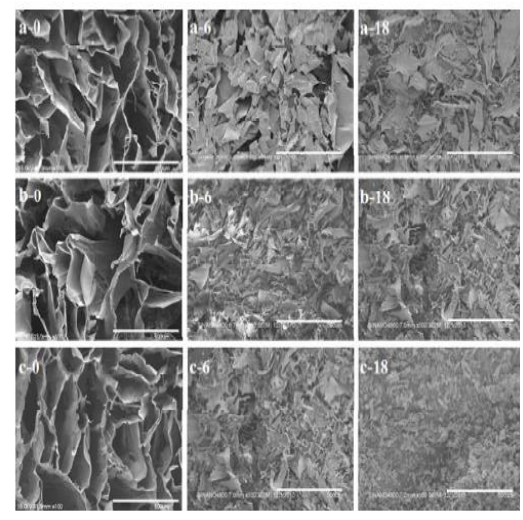

Fig. 2. SEM Evaluation of the derived scaffolds surface morphology: (a) $\mathrm{LiBr}$; (b) $\mathrm{Ca}\left(\mathrm{NO}_{3}\right)_{2}$; (c) $\mathrm{CaCl}_{2}$. The derived scaffolds were incubated in the enzyme solution for 0,144 and 432 hours. White bar indicates $500 \mu \mathrm{m}$. Reproduced from [42].

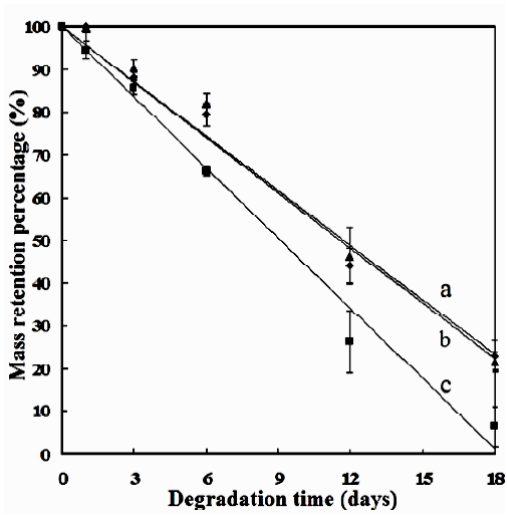

Fig. 3. Changes in mass retention to degradation time on SF-derived scaffolds: $(\boldsymbol{\Delta})$ $\mathrm{LiBr},(\diamond) \mathrm{Ca}\left(\mathrm{NO}_{3}\right)_{2},(\boldsymbol{-}) \mathrm{CaCl}_{2}$. The a, b and $c$ indicated the linear trendlines for the degradation profiles for derived scaffolds of the $\mathrm{LiBr}, \mathrm{Ca}\left(\mathrm{NO}_{3}\right)_{2}$ and $\mathrm{CaCl}_{2}$, respectively. Reproduced from [42].

The degradable level of the fibroin silk was associated with a lower cross-link level of $90 \%$. This indicates that the structure of molecular was controlled by the process of cross-linking managed the crystallization of the material which furthermore becomes the degradation rate controller [39]. The silk fibroin degradation depends on the 
content of silk II which is difficult to dissolve in water and silk structure that can be easily dissolved in water. Increased number of silk II can lead to an increase in the number of $\beta$-sheet structures and time for degradation process [40]. Silk fibroin was degraded more rapidly in water-insoluble silk fibroin with less number of b-sheet and was made by a controlled and extremely slow drying treatment $[41,40]$.

\subsection{Immunological response}

Immunogenicity associated with certain immune reactions to biomedical materials is an essential deliberation because it can cause serious effects. Sutura hypersensitivity is affected by the source of silk material [35]. The body's inflammatory reaction to the pure silk is very different from the de-gummed silk fibroin. The inflammatory reaction of silk film graft in vivo is less than that of collagen and polylactic acid film [43].

\subsection{Silk fibroin composite scaffolds}

Silk fibroin is frequently used for bone tissue engineering. In this case, silk fibroin is incorporated with other biomaterials such as calcium phosphate or collagen-based materials [44 - 46]. Scaffold silk fibroin for urological tissue engineering has been successfully prepared for the purpose of bladder and urethral restoration. Furthermore, silk fibroin scaffolds were tested on several animals. The test results showed strong regeneration of pod muscles as well as urothelium [47]. The membrane composites incorporating grapheme-silk fibroin silk with various mass compositions have been successfully produced by electrospinning techniques [48]. Microscopic observations indicate that the composite membrane has successfully combined the excellent mechanical strength of graphene with silk biocompatibility in mimicking the natural microenvironment of nerve cells in the development of nerves.

\subsection{Silk Fibroin Reinforcement}

Currently, the study in orthopedic is more focused on developing biomaterials for regenerating bone tissue. For this purpose, it has produced many biomaterials from various materials. However, only a few of them are used today because they fail to present materials with mechanical strength that are particularly suited to bone graft with load bearing application. Silk fibroin is one of native protein having good homogeneity especially in subordinate structures. Nowadays, the application of silk fibroin in bone graft engineering has provided an alternative solution in the supply of implantable biomaterials in cases of accidents that cause bone injuries to be reconstructed [49 - 52]. The use of silk fibroin has been compatible with some parameters such as biocompatibility and biodegradability as well as osteoconductivity $[53,49,50]$. 
Some researchers have been reported that silk fibroin-matrixed composites are particularly suitable for human bone graft $[54,55]$. Short silk fibers and $\mathrm{NaCl}$ particles as reinforcement have been added to silk fibroin-hydroxyapatite porous composites formed by isostatic compaction techniques [56]. The mechanical performance of composite after it was tested showed that the added shortened silk fibers can increase the flexural strength and fracture energy. It has been reported that the silk fibroin is a promising bone replacement material especially bone tissue such as cartilage repair due to its strength and biocompatibility as well as its easy manufacturing [35]. It was also reported by Youdmuang et al [57] that the utilization of silk-based fiber-hydrogel composite can improve mechanical properties in the development of functional cartilage manufacture as an alternative in getting the better of the limitedness of implantable materials. The silk fibroin-reinforced hydroxyapatite nanocomposite has been manufactured through chemical precipitation techniques. The resulting composites show that the HA precipitated silk fibroin scaffold has the significant higher strength compared to the silk fibroin scaffolds which was reinforced with silk fibroinhydroxyapatite [58]. The mechanical properties of varying kind of silk fibroin are shown in Table $1[59,60,35]$.

Table 1. The mechanical properties of varying kind of silk fibroin [59, 60, 35].

\begin{tabular}{|c|c|c|c|c|}
\hline \multicolumn{2}{|c|}{ Biomaterials Source } & $\begin{array}{c}\text { Young's } \\
\text { Modulus (GPa) }\end{array}$ & $\begin{array}{c}\text { Tensile Strength } \\
(\mathrm{MPa})\end{array}$ & $\begin{array}{c}\text { Elongation } \\
\text { at Break (\%) }\end{array}$ \\
\hline \multirow{2}{*}{ Bombyx mori silk } & with sericin & $5-12$ & 500 & 19 \\
\cline { 2 - 5 } & without sericin & $15-17$ & $610-690$ & $4-16$ \\
\hline Spider silk & & $11-13$ & $875-972$ & $17-18$ \\
\hline
\end{tabular}

The hydrogels composite based on silk fibroin reinforced with carbon nanotubes (CNTs) was successfully developed. SEM images shown in Fig. 4 illustrates the hydrogels composite enclosed by a mineral coating whose morphology is not affected by the hydrogel content.

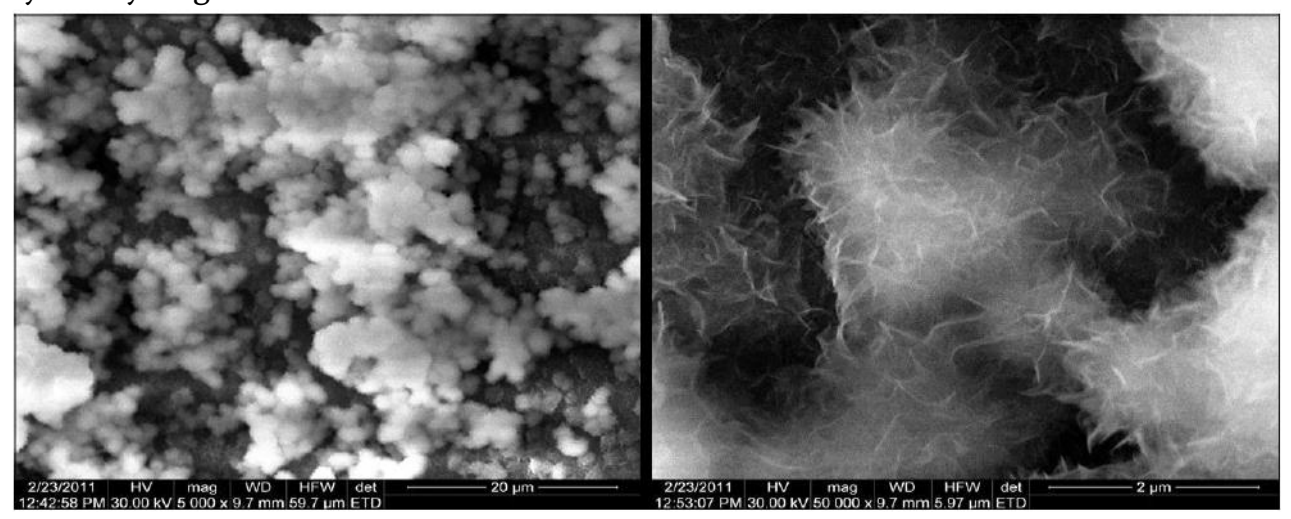

Fig. 4. SEM images that express the deposits material on the surface of silk fibroin-polyacrylamide hydrogels composite. Composites are incubated in simulated body fluid. Reproduced from [61].

\section{Conclusion}


Among of natural polymer, silk fibroin is considered as the most potential fiber for bone tissue engineering due to its good mechanical and biomedical behavior. In its application, it is incorporated with other materials to form composites. In the development, the silk fibroin is potentially developed as a reinforcement in thermoplastic-based composites for load bearing bone implant. It is based on the properties of biocompatible, degradable, and high mechanical strength fibroin silk.

\section{References}

1. A.J.T. Teo, A. Mishra, I. Park, Y.-J. Kim, W.-T. Park, Y.-J. Yoon, ACS Biomater. Sci. Eng., 2, 454-472 (2016)

2. J.L. Frodel, Fac plast surg. 24, 22-34 (2008)

3. M. Puska, A.J. Aho, P. Vallitu, In Tech, 55-72 (2011)

4. Purnomo, R. Soenoko, Y.S. Irawan, A. Suprapto, International Journal of Applied Engineering Research, 10, 28001-28012 (2015)

5. Purnomo, R. Soenoko, A. Suprapto, Y.S. Irawan, FME Transactions 44, 180-186 (2016)

6. Purnomo, R. Soenoko, Y.S. Irawan, A. Suprapto, Journal of Engineering Science and Technology 12, 1191-1203 (2017).

7. Purnomo, M. Subri, International Review of Mechanical Engineering 11, 87-93 (2017).

8. Purnomo, M. Subri, FME Transactions 46, 165-170 (2018)

9. I. Drosse, Injury. 39(Suppl 2):S9-S20 (2008)

10. M.M. Marquis, E. Lord, E. Bergeron, O. Drevelle, H. Park, F. Cabana, H. Senta, N. Faucheux, Front Biosci.14, 1023-1067 (2009)

11. Y. Khan, M.J. Yaszemski, A.G. Mikos, C.T. Laurencin. J Bone Joint Surg Am. 90, 3642 (2008)

12. P. Sierpinski, J. Garrett, J. Ma, P. Apel, D. Klorig, T. Smith, L.A. Koman, A. Atala, M.V. Dyke, Biomaterials, 29, 118-128 (2008)

13. H.-F. Ko, C. Sfeir, P.N. Kumta, Philos Trans A Math Phys Eng Sci, 28, 1981-1997 (2010)

14. A. Sionkowski, Progress in Polymer Science, 36, 1254-1276 (2011)

15. N. Kuboyama, H. Kiba, K. Arai, R. Uchida, Y. Tanimoto, U.K. Bhawal, Y. Abiko, S. Miyamoto, D. Knight, T. Asakura, N. Nishiyama, J Biomed Mater Res B Appl Biomater, 101, 295-302 (2013)

16. Y.-Y. Jo, .S.-G. Kim, K.-J. Kwon, H.Y. Kweon, W.-S. Chae, W.-G. Yang, E.-Y. Lee, H. Seok, Int J Mol Sci. 18, 858 (2017)

17. S. Bose, M. Roy, A. Bandyopadhyay, Trends Biotechnol, 30, 546-554 (2012)

18. S. Wu, X. Liu, K.W.K. Yeung, C. Liu, X. Yang, Mater. Sci. Eng. R-Rep. 80, 1-36 (2014)

19. J. Melke, S. Midha, S. Ghosh, K. Ito, S. Hofman, Acta Biomaterialia, 31, 1-16 (2016)

20. N. Kasoju, U. Bora, Adv. Healthc. Mater, 1, 393-412 (2012)

21. C.-Z. Zhou, F. Confalonieri, M. Jacquet, R. Perasso, Z.-G. Li, J. Janin, Proteins Struct. Funct. Bioinform. 44, 119-122 (2001)

22. K. Tanaka, S. Inoue, S. Mizuno, Insect Biochem. Mol. Biol. 29, 269-276 (1999)

23. S. Inoue, K. Tanaka, F. Arisaka, S. Kimura, K. Ohtomo, S. Mizuno, J. Biol. Chem. 275, 40517-40528 (2000)

24. E. Bini, D.P Knight, D.L. Kaplan, J Mol. Biol. 335, 2-40 (2004) 
25. V. Volkov, A.V. Ferreira, A. Cavaco-Paulo, Macromol. Mater. Eng., 300, 1199-1216 (2015)

26. Y. Qi, H. Wang, K. Wei, Y. Yang, R-Y. Zheng, I.S. Kim, K-Q. Zhang, Int J Mol Sci, 18, 237 (2017)

27. C. Vepari, D.L. Kaplan, Prog Polym Sci., 32, 991-1007 (2007)

28. R.L. Moy, L.A. Zalka. Am Fam Physician, 44, 2123-2128 (1991)

29. Y. Shen, S.L. Redmond, J.M. Papadimitriou, B.M. Teh, S. Yan, Y. Wang, M.D. Atlas, R.J Marano, M. Zheng, R.J. Dilley, Biomed Mater, 9, 015015 (2014)

30. Y. Cao, B. Wang, Int. J. Mol. Sci., 10, 1514-1524 (2009)

31. X. Tang, F. Ding, Y. Yang, N. Hu, H. Wu, X. Gu, J Biomed Mater Res A. 91, 166-74 (2009)

32. Y. Yang, X. Chen, F. Ding, P. Zhang, J. Liu, X. Gu, Biomaterials, 28, 1643-52 (2007)

33. D.W. Li, X. Lei, F.L. He, J. He, Y.L. Liu, Y.J. Ye, X. Deng, E. Duan, D.C. Yin, Int J Biol Macromol, 105, 584-597 (2017)

34. R.L. Horan, K. Antle, A.L. Collette, Y. Wang, J. Huang, J.E. Moreau, V. Volloch, D.L. Kaplan, G.H. Altman, 26, 3385-3393 (2005)

35. G.H. Altman, F. Diaz, C. Jakuba, T. Calabro, R.L. Horan, J. Chen, H. Lu, J. Richmond, D.L. Kaplan, Biomaterials, 24, 401-416 (2003)

36. H.K. Soong, K.R. Kenyon, Ophthalmol, 91, 479-483 (1984)

37. E. Rossitch, D.E. Bullard, W.J. Oakes, Childs Nerv. Syst., 3, 375-378 (1987)

38. B. Liu, Y-w Song, L. Jin, Z-j Wang, D-y Pu, S-q Lin, C. Zhou, H-j You, Y. Ma, J-m Li, L. Yang, K.L.P. Sung, Y-g. Zhang, Colloids and Surfaces B: Biointerfaces, 131, 122-128 (2015)

39. R. You, Y. Xu, G. Liu, Y. Liu, X. Li, M. Li, Polymer Degradation and Stability, 109, 226-232 (2014)

40. H.-J. Jin, J. Park, V. Karageorgiou, U.-J. Kim, R. Valluzzi, P. Cebe, D.L. Kaplan, Adv. Funct. Mater., 15, 1241-1247 (2005)

41. Q. Lu, X. Hu, X. Wang, J.A. Kluge, S. Lu, P. Cebe, D.L. Kaplan, Acta Biomater, 6, 1380-1387 (2010)

42. R. You, Y. Zhang, Y. Liu, G. Liu, M. Li, Natural Science, 5, 10-19 (2013)

43. L. Meinel, S. Hofmann, V. Karageorgiou, C. Kirker-Head, J. McCool, G. Gronowicz, L. Zichner, R. Langer, G. Vunjak-Novakovic, D.L. Kaplan, Biomaterials., 26, 147-155 (2005)

44. N. Panda, A. Biswas, K. Pramanik, S. Jonnalagadda, J. Biomed. Mater. Res. B Appl. Biomater. 00B, 1-12 (2014)

45. S. Miyamoto, R. Koyanagi, Y. Nakazawa, A. Nagano, Y. Abiko, M. Inada, C. Miyaura, T. Asakura, Journal of Bioscience and Bioengineering, 115, 575-578 (2013)

46. Y. Wang, X. Wang, J. Shi, R. Zhu, J. Zhang, Z. Zhang, D. Ma, Y. Hou, F. Lin, J. Yang, M. Mizuno, Scientific Reports, 6, 39477 (2016)

47. B.S. Sack, J.R. Mauney, C.R. Estrada Jr, Curr Urol Rep. 17, 16 (2016)

48. Y. Zhao, J. Gong, C. Niu, Z. Wei, J. Shi, G. Li, Y. Yang, H. Wang, J Biomater Sci Polym Ed. 28, 2171-2185 (2017)

49. E.S. Gil, J.A. Kluge, D.N. Rockwood, R. Rajkhowa, L. Wang, X. Wang, D.L. Kaplan, J Biomed Mater Res A., 99, 16-28 (2011)

50. D.N. Rockwood, E.S. Gil, S.H. Park, J.A. Kluge, W. Grayson, S. Bhumiratana, R. Rajkhowa, X. Wang, S.J. Kim, G. Vunjak-Novakovic, D.L. Kaplan, Acta Biomater, 7, 144-51 (2011)

51. B.B. Mandal, S.C. Kundu, Acta Biomater,5, 2579-2590 (2009)

52. B.B. Mandal, S.C. Kundu, Biomaterials, 30, 5019-5030 (2009) 
53. Y. Khan, M.J. Yaszemski, A.G. Mikos, C.T. Laurencin, J Bone Joint Surg Am,90, 36$42(2008)$

54. J.S. Yerramshetty, O. Akkus, Bone,42, 476-482 (2008)

55. K. Verdelis, Y. Ling, T. Sreenath, N. Haruyama, M. MacDougall, M.C.H. van der Meulen, L. Lukashova, L. Spevak, A.B. Kulkarni, A.L, Bone. 43, 983-990 (2008)

56. L. Shen-zhou, L. Jia-jia, Y. Shu-qin, L. Jian-bing, L. Ming-zhong, CRTER, 13, 67896792 (2009)

57. S. Yodmuang, S.L. McNamara, A.B. Nover, B.B. Mandal, M. Agarwal, T-A. N. Kelly, P-h.G. Chao, C. Hung, D.L. Kaplan, G. Vunjak-Novakovic, Acta Biomater, 11, 27-36 (2015)

58. S Behera, D Naskar, S Sapru, SC Kundu, Nanomedicine: nanotechnology, biology, and medicine, 13, 2017

59. J. Perez-Rigueiro, C. Viney, J. Llorca, M. Elices, J Appl Polym Sci., 75, 1270-1277 (2000)

60. P. Cunniff, S. Fossey, M. Auerbach, J. Song, D. Kaplan, W.W. Adams, R. Eby, D. Mahoney, D. Vezie, Polymers for Advanced Technologies, 5, 401-410 (1994)

61. C. Zahariaa, P.O. Stanescua, B. Galateanub, E. Vasilea, M.A. Pandelea, H. Cioflanc, ECCM16 - $16^{\text {TH }}$ European Conference On Composite Materials, Seville, Spain, 22-26 June 2014 